HOME

BROWSE

MORE $\nabla$

<PREV

NEXT >

Published Online: 23 August 2017

\title{
The Role of Data Range in Linear Regression
}

The Physics Teacher 55, 371 (2017); https:// doi.org/10.1119/1.4999736

M. A. Salgueiro da Silva and T. M. Seixas

View Affiliations

次

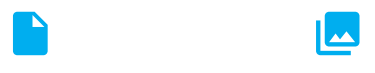

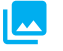

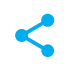

Topics -

\section{ABSTRACT}

Measuring one physical quantity as a function of another often requires making some choices prior to the measurement process. Two of these choices are: the data ranoe where measurements should focus and the 
number $(n)$ of data points to acquire in the chosen data range. Here, we consider data range as the interval of variation of the independent variable $(x)$ that is associated with a given interval of variation of the dependent variable $(y)$. We analyzed the role of the width and lower endpoint of measurement data range on parameter estimation by linear regression. We show that, when feasible, increasing data range width is more effective than increasing the number of data points on the same data range in reducing the uncertainty in the slope of a regression line. Moreover, the uncertainty in the intercept of a regression line depends not only on the number of data points but also on the ratio between the lower endpoint and the width of the measurement data range, reaching its minimum when the dataset is centered at the ordinate axis. Since successful measurement methodologies require a good understanding of factors ruling data analysis, it is pedagogically justified and highly recommended to teach these two subjects alongside each other.

\section{REFERENCES}

1.

T. M. Seixas and M. A. Salgueiro da Silva, "The importance of measurement data spacing," Phys. Teach. 53, 356-357 (Sept. 2015). https://doi.org/10.1119/1.4928351, Google Scholar, Scitation

2.

J. R. Taylor, An Introduction to Error Analysis, 2nd ed. (University Science Books, 1997), pp. 182-188. Note: in this reference, $a$ and $b$ are, respectively, the intercept and slope of the regression line. 
3.

P. R. Bevington and D. K. Robinson, Data Reduction and Error Analysis, 3rd ed. (McGraw-Hill Higher Education, New York, 2003), pp. 104-110. Google Scholar

4.

L. Kirkup, Data Analysis with Excel: An Introduction for Physical

Scientists (Cambridge University Press, 2002), pp. 217-226.

\section{Google Scholar}

5.

S. G. Rabinovich, Measurement Errors and Uncertainties: Theory and Practice, 3rd ed. (Springer, 2005), pp. 36-47. Google Scholar

6.

H. J. Berendsen, A Student's Guide to Data and Error Analysis

(Cambridge University Press, Cambridge, 2011), p. 89. Google Scholar, Crossref

7.

See Ref. 4, pp. 232-233. Google Scholar

8.

See Ref. 4, pp. 233-235. Google Scholar

(C) 2017 American Association of Physics Teachers. 


\section{Resources}

AUTHOR

LIBRARIAN

ADVERTISER

\section{General Information}

ABOUT

CONTACT

HELP

PRIVACY POLICY

TERMS OF USE

FOLLOW AIP PUBLISHING:

f $y$ in

Website @ 2018 AIP Publishing LLC. Article copyright remains as specified within the article. ${ }^{2}$ tion 